\title{
Mantendo a disciplina: procedimentos de gestão da sala de aula
}

Maintaining discipline: Classroom management procedures

\author{
1 Fábio Luiz da Silva fls.londrina@yahoo.com.br \\ 2 Fabiane Tais Muzardo biumuzardo@yahoo.com.br \\ 3 Julho Zamariam julho.zamariam@unopar.br
}

\footnotetext{
1 Doutor em História. Professor do Programa de Mestrado em Metodologias para o Ensino de Linguagens e suas Tecnologias. Professor do Colégo de Aplicação Pedagógica da Universidade Estadual de Londrina.

2 Doutoranda em História pela UFPR. Professora de História na Unopar.

3 Mestre em História. Professor de História na Unopar.
}

\section{Resumo}

O objetivo desse artigo é apresentar os resultados de uma pesquisa que buscou verificar as estratégias utilizadas por professores brasileiros para a gestão da sala de aula diante do comportamento perturbador dos alunos.Foi realizada pesquisa de campo com professores brasileiros de doze cidades, que responderam a um questionário que indagava sobre as estratégias adotadas diante da indisciplina e da continuidade do comportamento perturbador. A análise dos resultados permite perceber uma série de semelhanças e diferenças quanto às abordagens dos professores reveladas em pesquisas anteriores. No caso dos professores investigados, os dados recolhidos apontam para uma crise na autoridade dos professores em sala de aula, situação que os encoraja a deixar para outras instâncias - família ou equipe diretiva da escola - a solução dos casos de indisciplina.

\section{Palavras-chave}

Gestão em sala de aula. Indisciplina. Ensino. Autoridade. Aprendizagem.

\begin{abstract}
The purpose of this article is to present the results of a research that sought to discover the strategies used by Brazilian teachers to manage the classroom in the face of disruptive behavior of students. Field research was carried out with Brazilian teachers from twelve cities, who answered a questionnaire that inquired about the strategies adopted in the face of indiscipline and the continuity of disruptive behavior. The analysis of the results allows to perceive a series of similarities and differences regarding the approaches of the teachers revealed in previous researches. In the case of the investigated teachers, the collected data point to a crisis in the authority of teachers in the classroom, a situation that encourages them to leave to other instances - family or school board - to solve the cases of indiscipline.
\end{abstract}

\section{Keywords}

Classroom management. Indiscipline. Teaching. Authority. Learning.

\section{Como você deve citar?}

SILVA, Fábio Luiz da; MUZARDO, Fabiane Tais; ZAMARIAM, Julho. Mantendo a disciplina: procedimentos de gestão da sala de aula. Cadernos UniFOA, Volta Redonda, n. 37, p. 81-92, ago. 2018. 


\section{INTRODUÇÃO}

O tema da indisciplina está presente nas escolas desde a origem dessa instituição social pois, como nos esclarecem Bissonette, Gauthier e Castonguay (2016), desde que a escola existe, espera-se que os professores eduquem as novas gerações no sentido de ensinar o conhecimento necessário para a vida em sociedade e no sentido de ensinar os valores que moldarão o seu comportamento. John Amos Comenius em seu livro Orbis Sensualim Pictus, publicado em 1685, por exemplo, descreve uma sala de aula na qual "9. Alguns conversam, 10. E outros se comportam de maneira desrespeitosa e descuidada"(1887 [1685], p. 119, tradução nossa) e que seriam castigados pelo professor com uma vara de metal. Na literatura, temos diversos exemplos de como era assegurada, ou não, a disciplina em sala de aula. Montgomery (2009), no primeiro volume da série de romances cuja protagonista é a órfã Anne Shirley, apresenta algumas cenas deveriam ser bastante comuns nas escolas do início do século XX. Em certo momento, Anne foi castigada por alguma travessura que tinha feito, ficando em pé na frente da turma, ao lado da lousa, o restante do tempo da aula. Até mesmo em um desenho animado da Disney, Teachers are People, de 1952, cujo personagem principal é o Pateta, o tema da indisciplina é abordado. 0 tempo todo aquilo que o narrador afirma é contraditado pelo desenrolar da história. Por exemplo, enquantoele diz que o professor sabe lidar com qualquer situação dignamente, o Pateta é quase atropelado tentando atravessar a rua em direção à escola, onde os alunos o esperam fazendo algazarra. Qualquer professor, em qualquer lugar do mundo, é capaz de identificar as diversas situações vivenciadas pelo Pateta. Em outras palavras, os problemas de gestão da sala de aula enfrentados pela personagem não diferem muito daqueles que os professores cotidianamente encontram em nossas escolas.

Boto (2017) descrevendo o período do surgimento da escola moderna, no intuito de compreender essa instituição hoje, em diversos momentos revela como preocupação com o comportamento dos alunos acompanhou o desenvolvimento da escola até nossos dias. Podemos afirmar, portanto, que o comportamento dos alunos na escola, especialmente na sala de aula, tem sido uma das principais preocupações de muitos professores e especialistas em educação há muito tempo.Em 1848, por exemplo, Henry Barnard publicou um livro com os resultados de suas investigações a respeito da situação das escolas estadunidenses. Entre as muitas informações que recolheu, estão as normas para o comportamento dos alunos em sala de aula, que não diferem muito das que podemos encontrar em nossas escolas. Esse autor reproduz - entre outras - a seguinte norma aplicada nas escolas de Rhodelsland, "Todos os alunos que [...] usarem ou escreverem qualquer linguagem profana ou não-casta, ou desenharem quaisquer representações obscenas, [...] serão punidos na proporção da natureza e extensão da infração [...]" (BARNARD, 1848, p. 291, tradução nossa).Em 1908, outro exemplo, Willian Chandler Bagley publicou, nos Estados Unidos, um livro intitulado Classroom Management: its principlesandtechnique, que tinha por objetivo auxiliar os professores em seu ofício, especialmente no que dizia respeito à organização da classe. Como no seguinte trecho, "a primeira condição para uma disciplina efetiva é o respeito pela autoridade do professor. Caso esse respeito seja suficientemente forte, todos os problemas disciplinares estarão resolvidos e a solução será comparativamente simples" (BAGLEY, 1908, p. 93, tradução nossa).

Pesquisas recentes também têm demonstrado que a indisciplina é um problema encontrado em diversas regiões do planeta. Lewis et al (2005) relataram a percepção dos alunos a respeito das estratégias de gestão da sala de aula relativas à disciplina na Austrália, China e Israel. Comparando os pontos de vista dos alunos de diferentes contextos nacionais, os pesquisadores discutiram as diversas implicações de suas descobertas. Entre elas estava o fato de as estratégias de gestão de sala de aula consideradas eficazes, ou não, eram semelhantes nos três países.Akin-Little, Little e Laniti (2007) também realizaram uma pesquisa sobre a gestão da sala de aula com professores dos Estados Unidos e da Grécia. Foram verificados, dentre outras coisas, os procedimentos empregados pelos professores 
diante do comportamento indisciplinado dos alunos e diante da continuidade desse tipo de comportamento. Em ambos os países, os resultados foram bastante semelhantes, o que levou os pesquisadores a realizarem considerações sobre a importância de pesquisas do tipo cross-cultural. Reynolds et al (2002) também destacam a importância de se realizarem pesquisas desse tipo, pois, segundo eles, vivemos em um mundo cada vez menor, isto é, mais conectado. As interações entre os cidadãos de diferentes países, seja fisicamente, seja eletronicamente, permitem a disseminação do conhecimento e de comportamentos de uma maneira que era impossível antes.

Gu, LaieYe (2011) analisaram problemas de comportamentos de alunos em dez países, discutindo a atitude dos professores, o envolvimento dos pais e as influências dos problemas de comportamento no desempenho acadêmico dos alunos. Os pesquisadores concluíram, entre outras coisas, que tais problemas têm forte relação com a performance dos alunos. Isto significa que a redução desses problemas deve melhorar o desempenho escolar dos alunos. Nasey (2012), em sua dissertação de mestrado, estudou a questão da gestão da sala de aula nas escolas da Nova Zelândia. Utilizando o mesmo instrumento de pesquisa de Akin-Little, Little e Laniti (2007), a pesquisadora comparou as estratégias de gestão do comportamento dos alunos neozelandeses, estadunidenses e gregos. Também Silva et al (2016) investigaram as práticas disciplinares de professores de duas cidades brasileiras e chegaram à conclusão de que os problemas de indisciplina são bastante comuns, mesmo em contextos diferentes. Em 2015, Cerit eYüksel publicaram estudo sobre as percepções de professores da Turquia e da Letônia a respeito da gestão da sala de aula. Uma das conclusões apresentadas afirma que os professores de ambos os países possuem percepções semelhantes sobre esse tema. Mais recentemente, Bissonette, Gauthier e Castonguay (2016) procuraram compreender quais estratégias de gestão da sala de aula estão associadas aos melhores resultados dos alunos, realizando análise dos resultados de pesquisas sobre esse tema. Todas essas pesquisas parecem confirmar a posição de Reynolds et al (2002, p. 279, tradução nossa), quando afirmam que "no nível da sala de aula, os poderosos elementos da expectativa, gestão, clareza e da qualidade da instrução transcendem a cultura", ou seja, a gestão da sala de aula é um dos elementos determinantes do ensino e da aprendizagem em qualquer cultura.

Por outro lado, em pesquisa realizada por Ledo (2009), que revisou a produção acadêmica sobre o tema indisciplina, tornou-se evidente a ausência da temática da indisciplina ou da gestão da sala de aula nos cursos brasileiros de Pedagogia e de Licenciatura. Na mesma direção, Aquino (2016) investigou artigos 35 publicados sobre o tema entre os anos de 1995 e 2015 e observou que, apesar da indisciplina figurar como uma das principais reclamações dos professores, "não consiste em uma preocupação explícita entre os pesquisadores do campo" (AQUINO, 2016, p. 668). Assim, pode-se afirmar que existe um imenso campo, no Brasil, para pesquisas sobre a indisciplina e gestão da sala de aula, principalmente aquelas que objetivem lançar luz sobre o que ocorre na caixa preta da educação, a sala de aula (BRASTER; GROSVENOR; ANDRÉS, 2011).

Em contrapartida, Silva (2016) realizou um estudo sobre as pesquisas brasileiras a respeito da indisciplina e da gestão da sala de aula e concluiu que há um crescente interesse na utilização da expressão gestão da sala de aula na literatura acadêmica e profissional em Educação, apesar de essa temática se encontrar mais consolidada na América do Norte. Porém, mesmo com o aumento da preocupação acadêmica com a temática, segundo Silva (2016), as ações disciplinares dos professores ainda são tratadas em tom de denúncia, que considera as estratégias de gestão da sala de aula como vestígios de uma pedagogia ultrapassada. Por outro lado, há estudos que apontam a importância de realizar-se pesquisas nessa área. A Organização para a Cooperação e Desenvolvimento Econômico (OCDE) realizouuma pesquisa, em 2013, em diversos países do mundo e, entre outras informações, obteve o seguinte: os professores brasileiros gastam cerca de $20 \%$ de cada aula na tentativa de manter a ordem em sala. Além disso, a pesquisa ainda revelou que aproximadamente $53 \%$ dos professores afirmaram gastar muito tempo no início das aulas na espera pela atenção dos alunos, percentual muito 
próximo daquele que informou haver muito barulho em suas salas de aula, $54,5 \%$ (OCDE, 2014). Segundo Ferreira, Santos e Rosso (2016), as pesquisas brasileiras sobre a questão da indisciplina revelam que, na visão da maioria dos professores, os problemas de comportamento dos alunos têm origem apenas na sociedade ou nas famílias, raramente são entendidos como ligados especificamente à questão pedagógica. Simultaneamente, afirmam esses autores, há uma evidente carência na formação dos professores brasileiros em relação à gestão da sala de aula, que comumente não diferenciam autoridade e autoritarismo, bem como democracia e permissividade.

A indisciplina tem sido apontada como um dos principais entraves à melhoria da aprendizagem, além de dificultar a vivência responsável em sociedade (LEWIS et al, 2005). Bissonette, Gauthier e Castonguay (2016) seguem na mesma direção ao afirmarem que uma gestão de sala de aula eficaz é condição imperiosa, apesar de não suficiente, para um ensino eficaz. Esses autores lembram, também, que mesmo quando os professores mais diligentesprocuram utilizar atividades interessantes, não conseguirão evitar problemas de comportamento dos alunos.Diante disso, torna-se evidente a necessidade de estudos que apontem quais as abordagens válidas para a gestão da sala de aula. Em outras palavras, é preciso descobrir as estratégias que permitam o controle do comportamento dos alunos por meio de procedimentos que facilitem o ensino.

No entanto, para Little e Akin-Little (2003), não existe um único procedimento de gestão da sala de aula, mas há uma série de técnicas e procedimentos que podem ajudar os professores a gerenciar melhor suas salas de aula. Essas técnicas dependem do ambiente da sala de aula, dos tipos de comportamentos perturbadores, do nível de envolvimento dos alunos e da gravidade dos problemas de comportamento. No Brasil, há poucas opções de livros que possam orientar o professor na direção de aperfeiçoar a gestão em sala de aula. Destacam-se duas publicações, ambas traduções de originais em inglês. Weinstein e Novodvorsky (2015) procuraram indicar as melhores estratégias para o professor que trabalhe com adolescente, indicando possibilidades para diversas situações desafiadoras, mas frequentes em sala de aula. Rogers (2008) apresenta uma relação de habilidades que o professor deveria possuir para desempenhar o ofício do ensino com eficácia. No caso desse último autor, o diferencial é a explícita compreensão das dificuldades e limitações humanas dos professores, o que faz dessa obra um importante texto para reflexão. Considerando o exposto, o objetivo dessa pesquisa foi levantar as estratégias utilizadas pelos professores brasileiros para gestão da sala de aula, relacionadas às dificuldades mencionadas.

\section{METODOLOGIA}

Para descrever os procedimentos adotados pelos professores que configuram as estratégias de gestão da sala de aula, foi realizada uma pesquisa de campo do tipo quantitativo. Os participantes foram 87 professores que lecionam em escolas públicas da Educação Básica, de doze cidades brasileiras. Todos os professores que participaram dessa pesquisa assinaram um Termo de Consentimento Livre e Esclarecido, que é um documento por meio do qual os indivíduos participantes ficam cientes dos procedimentos da investigação e dão a sua concordância em participar do processo. Como instrumento de coleta de dados, foi utilizada parte do questionário aplicado por Akin-Little, Little eLaniti (2007) a professores dos Estados Unidos e da Gréciae por Nasey (2012) a professores da Nova Zelândia. 0 instrumento, originalmente escrito em língua inglesa, foi traduzido para o português pelos próprios autores da pesquisa.Optou-se, nesse estudo, por verificar apenas as estratégias reativas, que foram divididas, no instrumento de pesquisa, em dois grupos: as estratégias de resposta ao comportamento inadequado dos alunos em sala de aula e as estratégias de resposta à continuidade do comportamento inadequado em sala de aula. A pesquisa foi aprovada pelo Comitê de Ética em Pesquisa (CAAE 66478617.0.0000.0108, parecer 2.183.621). 


\section{RESULTADOS}

Comparando-se os resultados obtidos pela pesquisa com os dados levantados internacionalmente, foi possível observar algumas similaridades e algumas diferenças. A tabela 1 apresenta os resultados para as respostas dos professores aos comportamentos inadequados dos alunos em sala de aula, permitindo a comparação com dados de outras pesquisas.

Tabela 1 - Respostas dos professores ao comportamento inadequado (em \%)

\begin{tabular}{|c|c|c|c|c|}
\hline & $\begin{array}{l}\text { Brasil } \\
(n=87)\end{array}$ & $\begin{array}{c}\text { EUA } \\
(n=149)\end{array}$ & $\begin{array}{l}\text { Grécia } \\
(\mathrm{n}=97)\end{array}$ & $\begin{array}{c}\text { Nova } \\
\text { Zelândia } \\
(n=53)\end{array}$ \\
\hline Faz uma reprimenda oral ao(s) aluno(s) & 77 & 83 & 74 & 93 \\
\hline Olha com desaprovação para o(s) aluno(s) & 48 & 80 & 72 & 77 \\
\hline Movimenta-se para perto do(s) aluno(s) & 48 & 83 & 75 & 64 \\
\hline $\begin{array}{l}\text { Escreve o nome do(s) aluno(s) em um } \\
\text { registro }\end{array}$ & 32 & 25 & 22 & 42 \\
\hline Ignora o comportamento indisciplinado & 03 & 33 & 30 & 40 \\
\hline $\begin{array}{l}\text { Ignora o comportamento indisciplinado } \\
\text { e reconhece o bom comportamento de } \\
\text { outro(s) aluno(s) }\end{array}$ & 08 & 55 & 48 & 79 \\
\hline
\end{tabular}

Fonte: dados da pesquisa; Akin-Little, Little e Laniti (2007); Nasey (2012), tradução nossa

Verificou-se que a "reprimenda oral" foi a estratégia mais utilizada pelos professores brasileiros o que se apresentou como uma similaridade entre as ações dos professores dos quatro países. Por outro lado, as estratégias com maiores diferenças foram aquelas que indicam que os professores brasileiros pesquisados não costumam simplesmente ignorar o comportamento indisciplinado - no sentido de evitar o confronto -, nem utilizam dessa estratégia em conjunto com o elogio ao bom comportamento de outro aluno. Akin-Little, Little eLaniti (2007) sugerem que esse tipo de reação por parte dos professores pode servir como reforço positivo para o comportamento inapropriado, pois pode fornecer ao aluno indisciplinado a atenção que ele está,inconscientemente, solicitando. Weinstein e Novodvorsky (2015) afirmam que a não intervenção deliberada e consciente pode ser a melhor estratégia, especialmente nos casos em que o comportamento inadequado for breve e discreto.

As demais estratégias apresentaram diferenças menores, mas que podem ser consideradas significativas. Entre os professores brasileiros pesquisados, $48 \%$ afirmaram utilizar-se da estratégia do "olhar de desaprovação", sendo que, nos três outros países, esse resultado foi superior a $70 \%$. Movimentar-se para perto do aluno que apresenta comportamento inadequado foi estratégia apresentada por $48 \%$ dos professores brasileiros pesquisados, uma porcentagem também inferior àquela dos outros países. Gauthier et al (2013) fizeram uma ampla revisão das pesquisas a respeito da gestão da sala de aula e concluíram que os professores eficientes são, justamente, aqueles que se utilizam de sinais não-verbais e não-obstrutores, como contato direto com os olhos e proximidade com os alunos. Mesmo quando fazem interferências verbais, elas devem ser simples e diretas (GAUTHIER et al, 2013). Weinstein eNovodvorsky (2015) também indicam que o olhar do professor e a sua movimentação para próximo do aluno são exemplos de intervenção não verbal discreta, mas que informam aos alunos a atenção do professor. Esse tipo de estratégia de gestão da sala de aula permite ao professor lidar com o comportamento inadequado sem distrair os demais alunos, preservando o ritmo do ensino e a qualidade da aprendizagem. Essa ação do professor também incentiva "[...] os alunos a assumirem a responsabilidade por retornar à tarefa" (WEINSTEIN; NOVODVORSKY, 2015, p. 296), pois o evento pertur- 
bador não se prolonga. Rogers (2008) afirma que o professor deve estar consciente da sua linguagem corporal, inclusive de seu olhar, para garantir a expressão da confiança necessária à sua autoridade. Seguindo na mesma direção, Montouro e Lewis (2015) afırmam que os alunos preferem os professores que intervêm de forma discreta nos casos de indisciplina e que, em diversas partes do mundo, os alunos expressam aversão às estratégias coercitivas de gestão da sala de aula.

A respeito da estratégia de o professor utilizar-se da anotação do nome do aluno indisciplinado em algum tipo de registro, o resultado brasileiro foi superior aos demais países, mas muito próximo do resultado observado na Nova Zelândia. No caso brasileiro, $32 \%$ dos professores pesquisados afirmaram que usam essa estratégia quando estão diante de um aluno com comportamento inadequado. $\mathrm{Na}$ Grécia e nos Estados Unidos, o resultado foi inferior, $22 \%$ e $25 \%$ respectivamente. Somente no caso da Nova Zelândia, o resultado foi superior aobrasileiro, com $42 \%$. Uma possibilidade de explicação para um terço dos professores brasileiros registrarem por escrito os comportamentos inadequados, pode ser encontrada, talvez, na crise da autoridade dos professores brasileiros em sala de aula(SOARES, 2012; CARVALHO, 2015). Agindo dessa forma, os professores parecem desejar se resguardar de questionamentos futuros, seja da família, seja da equipe diretiva da escola em relação à suas decisões em sala.

Quando ocorre de os alunos continuarem a apresentar comportamentos inadequados, os professores costumam tomar outras atitudes. A persistência dos alunos na indisciplina gera nos professores a necessidade de estratégias mais "duras" com o objetivo de manter o controle da turma e possibilitar o ensino. Na Tabela 2,é possível observar os resultados para as estratégias adotadas pelos professores pesquisados quando os alunos continuam com o comportamento inadequado, mesmo depois de terem sido utilizadas as estratégias anteriormente citadas.

Tabela 2 - Resposta dos professores à continuidade do comportamento inadequado (em \%)

\begin{tabular}{lcccc}
\hline & $\begin{array}{c}\text { Brasil } \\
(\mathrm{n}=84)\end{array}$ & $\begin{array}{c}\text { EUA } \\
(\mathrm{n}=149)\end{array}$ & $\begin{array}{c}\text { Grécia } \\
(\mathrm{n}=97)\end{array}$ & $\begin{array}{c}\text { Nova } \\
\text { Zelândia } \\
(\mathrm{n}=53)\end{array}$ \\
\hline $\begin{array}{l}\text { Indica trabalho extra (mais tarefa de casa, } \\
\text { cópia, pesquisa extra etc) }\end{array}$ & 05 & 10 & 16 & 19 \\
\hline Retira do(s) aluno(s) algum benefício & 26 & 63 & 67 & 57 \\
\hline $\begin{array}{l}\text { Retira o(s) aluno(s) de sala de aula para o } \\
\text { corredor ou pátio }\end{array}$ & 12 & 39 & 29 & 36 \\
\hline $\begin{array}{l}\text { Envia o(s) aluno(s) para a diretoria ou sala da } \\
\text { pedagogia }\end{array}$ & 70 & 56 & 53 & 43 \\
\hline $\begin{array}{l}\text { Envia recado para os pais } \\
\text { (20 }\end{array}$ & 58 & 62 & 53 & \\
\hline
\end{tabular}

Fonte: dados da pesquisa; Akin-Little, Little e Laniti (2007); Nasey (2012), tradução nossa

Nesse caso, também houve similaridades e diferenças entre os resultados brasileiros e aqueles dos outros países. A estratégia que apresentou maior similaridade foi: "envia recado para os pais", que ficou entre $43 \%$ e $62 \%$ e que representou a segunda opção mais utilizada pelos professores brasileiros. A primeira foi "envia o(s) aluno(s) para a diretoria ou sala da pedagogia", apontada como estratégia utilizada por $70 \%$ dos professores brasileiros pesquisados.Nesse caso, destaca-se a diferença entre o Brasil e a Nova Zelândia no uso da estratégia de enviar o aluno indisciplinado para o diretor:70\% e $36 \%$, respectivamente. Weinstein e Novodvorsky (2015) e Rogers (2008) alertam para a necessidade de recorrer-se a esse tipo de estratégia apenas quando as perturbações forem graves, pois pode ocorrer 
que os alunos consigam justamente o que desejam: ficar fora da sala de aula. De maneira semelhante à estratégia já citada, de anotar os casos de indisciplina em algum tipo de documento, a tendência dos professores pesquisados em enviar os alunos para a diretoria ou equipe pedagógica e comunicar os pais a respeito dos problemas de comportamento dos filhos pode sinalizar mais uma vez a crise da autoridade dos professores. É provável que essa situação indique, também, que os professores não conseguem exercer uma liderança adequada em sala de aula, que é uma condição necessária para a construção de um clima escolar positivo (REYNOLDS et al, 2016).Ainda sobre a prática de comunicar os pais a respeito do comportamento inadequado (pressupomos que o comportamento adequado não é comunicado) é preciso refletir sobre o impacto que essa prática tem sobre a relação da escola com as famílias, caso esse seja um dos poucos momentos de contato entre professores e pais.

As maiores diferenças foram apresentadas pelas estratégias: "retirar privilégios" e "enviar para o corredor ou pátio". Em ambos os casos, os professores brasileiros pesquisados indicaram que utilizam pouco dessas estratégias. No primeiro caso, o resultado brasileiro foi de $26 \%$, enquanto nos demais países foi superior a $50 \%$. No segundo caso, o resultado brasileiro foi de $12 \%$, e o resultado médio dos outros países foi de $37,6 \%$. Talvez os professores prefiram, ao retirar o aluno de sala de aula, enviá-los para a diretoria ou setor pedagógico em razão da perturbação que alunos fora de sala possam causar aos demais professores.

\section{DISCUSSÃO}

Assumiu-se nesse estudo que a "ordem é um pré-requisito universal para que ocorra um ensino efetivo" (SHIMAHARA, 2013, p. 5, tradução nossa), apesar das diferenças culturais que existem entre os países postos em discussão. Ning et al (2015) analisaram a relação entre o clima disciplinar em sala de aula e o desempenho em leitura dos 65 países que participam do Programa de Avaliação Internacional de Estudantes (PISA) - de 2009 - e concluíram que era positiva em 53 desses países. Em outras palavras, na maioria dos casos uma melhor disciplina em sala de aula favoreceu um aprendizado mais efetivo. Para Gauthier et al (2013), os ganhos de aprendizagem dos alunos estão intimamente relacionados às habilidades que o professor tem de gerira sala de aula, uma vez que o esforço deles, nas tarefas que Ihes são atribuídas, é maximizado. Para Reynolds et al (2016), é preciso maximizar o tempo de ensino e aprendizado, evitando incidentes disciplinares durante a aula.

Consequentemente, pode-se afirmar que bons gestores de classe tendem a ser bons professores também e vice-versa. Isso ocorre em virtude do fato de os professores com grandes habilidades de gestão da sala de aula tomarem, preferencialmente, medidas preventivas em relação à indisciplina, fazendo com que a frequência dos comportamentos inadequados diminua. 0 professor mais eficiente procura utilizar a maior parte do tempo da aula ensinando o conteúdo, utilizando as melhores estratégias para que seus alunos aprendam o máximo possível. Gauthier, Bissonnette e Richard (2014), referindo-se à pesquisa realizada por Reynolds et al (2002) em nove países, de quatro continentes, apresentam como uma das principais características das escolas eficientes o fato de o professor supervisionar continuamente os alunos, maximizando, portanto, o ensino e a aprendizagem. Rogers (2008, p. 24) afirma que essa ação do professor deve ocorrer "de uma maneira o menos intrusiva possível, o que mantém o relacionamento funcional e civilizado". Mesmo os alunos consideram que bons professores têm expectativas claras em relação ao comportamento e à aprendizagem (MONTUORO; LEWIS, 2015).

Ma e Willms (2004),estudando alunos de escolas dos Estados Unidos, concluíramque as interrupções nos processos de ensino e de aprendizagem configuram o principal efeito negativo da ocorrência da indisciplina. Mais recentemente, Korpershoek et al (2016) realizaram uma revisão das pesquisas sobre os efeitos da gestão da sala de aula nos resultados acadêmicos, comportamentais, 
emocionais e motivacionais dos alunos e concluíram que uma boa gestão da sala de aula é condição essencial para o ensino eficaz, ou seja, para a aprendizagem dos alunos. Segundo esses autores, isso ocorre provavelmente em razão do fato de as melhores práticas de gestão aumentarem o tempo dedicado ao ensino, o que cria mais oportunidades de aprendizagem. Por outro lado, Lewis et al (2008) afirmam que alunos cujos professores são excessivamente rigorosos tendem a ter atitudes negativas em relação ao conteúdo que está sendo ensinado, o que significa a necessidade de ponderação nas ações docentes em sala de aula.

Os dados coletados não permitem afirmar em qual dos países citados na pesquisa háos professores que realizam a melhor gestão da sala de aula e, portanto, possibilitariam um melhor ensino. Esse não se configurou um objetivo desse estudo.Podemos indicar, no entanto, que em os problemas de indisciplina existem em todos eles e que, com maior ou menor intensidade, os professores dos quatro países procuraram adotar estratégias de gestão de sala de aula que permitissem a eles ensinar com eficácia. Assim como aqueles professores aos quais Bagley (1908) se dirigia, há mais de cem anos, em sua obra sobre a gestão da sala de aula; ou então, antes ainda, os professores investigados por Barnard (1848).

Apesar dessa questão ser antiga e geral, no Brasila indisciplina e a deficiência na gestão da sala de aula possuem dimensões preocupantes. Moriconi e Bélanger (2015) analisaram os resultados da Teachingand Learning International Survey (TALIS), de 2013, e concluíram que professores do Brasil, do Chile e do México afirmaram conviver com elevada porcentagem de problemas comportamentais em suas aulas. Nesse caso, os professores brasileiros revelaram gastar muito tempo para estabelecer e manter a ordem em sala de aula. Para esses autores, além da redução do tempo de ensino do conteúdo, essa situação dificultaria a permanência e a capacitação dos professores, pois a indisciplina seria um dos motivos do abandono da profissão. É possível concluir, portanto, que estratégias de gestão da sala de aula reativas, que exigem muito tempo ou que excluem o aluno indisciplinado da sala aula tendem a prejudicar ainda mais o ensino e a aprendizagem. Afinal, segundo Lo, Vicent e Robinson-Ervin (2015, p. 411 , tradução nossa), "o objetivo geral da gestão da sala de aula é minimizar a interrupção para que os professores possam ensinar e os alunos possam aprender" ou como afirma Rogers (2008, p. 71), "a habilidade e a prática de ensinar de forma efetiva e de administrar comportamentos perturbadores são cruciais para a efetividade da aprendizagem de qualquer grupo".

Ledo (2009) aponta, simultaneamente, para a importância da formação docente e para a quase ausência dessa formação em relação à gestão da sala de aula, no Brasil. É evidente que, para minorar os problemas de indisciplina em sala de aula, faz-se mister investir na capacitação docente, mas isso não chega a sanar o problema. Ma e Willms (2004), por exemplo, consideram que tratar a indisciplina apenas no nível da sala de aula é insuficiente, pois existem comportamentos inadequados fora dela que podem estar relacionados ao que ocorre em sala. Assim, "os gestores da escola precisam desempenhar um papel proativo no estabelecimento e manutenção de um clima disciplinar positivo, em vez de lidar, principalmente, com os alunos indisciplinados enviados para a secretaria da escola pelos professores ou alunos com problemas com a lei."(MA; WILLMS, 2004, p. 183, tradução nossa). Essa advertência parece ser bastante útil para o caso brasileiro, considerando que mais de $70 \%$ dos professores pesquisados encaminham para a diretoria os alunos que mais apresentam comportamento reiteradamente inadequado. Por isso, pesquisas como esta, mesmo de tamanho reduzido diante do número de professores existentes, são úteis para fomentar novos estudos e reflexões a respeito de temas da relacionadas à indisciplina e à gestão da sala de aula, de maneira que seja possível construir um conjunto de conhecimentos teoricamente fundamentado e realmente útil para orientar os professores no dia-a-dia de seu trabalho de ensinar às novas gerações o conhecimento historicamente acumulado pela humanidade. 


\section{CONCLUSÃO}

A escola moderna, tal como a concebemos, já surgiu com o objetivo de ensinar, além dos conteúdos, determinados comportamentos. Como nos lembra Boto (2017, p. 291), "a escola configura-se como instituição civilizadora". Por isso a preocupação com a indisciplina em sala de aula, fenômeno inserido na longa duração da história da educação e disseminado pelo mundo à medida em que a modernidade ganhava a hegemonia, a reboque dos colonialismos, imperialismos e, mais recentemente, da globalização. Tal constatação não deve ser entendida como simples negação da necessidade de autoridade ou de disciplina em sala de aula, como poderiam pensar alguns. Pelo contrário, essa consideração é colocada como demonstração da importância do tema caso desejemos uma escola melhor.

Por isso, é preciso refletir sobre a formação dos professores e sobre a estrutura das escolas que mantêm os docentes brasileiros preferindo resolver a indisciplina cotidiana em suas salas de aula por meio da retirada dos alunos e encaminhamento para a uma suposta autoridade superior, seja do diretor, seja da família. A solução para isso, ou seja, a construção de melhores alternativas somente virá pela reconstrução da autoridade dos professores. Esse processo, por sua vez, depende da identidade profissional que se pretenda relacionar aos docentes das escolas brasileiras. Pesquisas como esta, aqui apresentada, objetivam contribuir para esse fim, procurando entender como os professores agem em sala de aula, em nosso caso, diante dos comportamentos indisciplinados dos alunos.

Contudo, apesar de existir um aumento significativo das pesquisas no campo da gestão em sala de aula no Brasil, como mencionado, há ainda a necessidade de mais estudos sobre esse tema, relacionando-o a problemáticas que extrapolem a questão da indisciplina, principalmente. Nesse sentido, esta pesquisa vem somar-seàs tentativas que buscam refletir sobre a prática docente em território brasileiro, de modo a poder colaborar para a melhoria do ensino. Contudo, ao realizar uma análise comparativa entre as práticas de gestão de sala de aula, não se considerou as diferenças e especificidades culturais de cada um dos países envolvidos, pois limitamo-nos a apontar possíveis fatores que podem influenciar na ação dos professores. Além disso, a amostra de professores que fez parte da pesquisa foi pequena. Desse modo, nota-se a necessidade de pesquisas mais extensas para confirmar os dados levantados. Futuras pesquisas, que envolvam um número maior de professores e que considerem outros componentes da escola, como alunos e equipe pedagógica, além de ponderar a respeito das variáveis culturais e sociais, poderão levar a novas descobertas e posicionamentos em relação à prática da gestão da sala de aula. 


\section{REFERÊNCIAS}

AKIN-LITTLE, K. A.; LITTLE, S. G.; LANITI, M. Teachers' use of classroom management procedures in the United States and Greece: a cross-cultural comparison. SchoolPsycologyInternational, v. 28, n.1, 2007, p. 53-62.doi:10.1177/0143034307075680

AQUINO, J. G. Indisciplina escolar: um itinerário de um tema/problema de pesquisa. Cadernos de Pesquisa, v. 46, n. 161, jul./set., 2016, p. 664-692. doi: 10.1590/198053143670

BAGLEY, W. C. Classroom management: Its principles and technique. New York: The MacMillan Company, 1908.

BARNARD, H. School architecture or contributions to the improvement of school-houses in The United States. New York: A. S. Barnes \& Co, 1848.

BISSONNETTE, S.; GAUTHIER, C.; CASTONGUAY, M. L'EnseignementExplicite des Comportaments: pour une gestion efficace des élèvesen classe dans l'école.Quebec: CheneliéreÉducation, 2016.

BOTO, Carlota. A Liturgia escolar na idade moderna. Campinas: Papirus, 2017.

BRASTER, S.; GROSVENOR, I.; ANDRÉS, M. M. P. The Black Box of Schooling: a Cultural History of the Classroom. Brussels: PIE Peter Lang, 2011.

BROPHY, J. History of research on classroom management. In EVERTSON, C. M.; WEINSTEIN, C. (Orgs.) Handbook of classroom management: research, practice and contemporary isues. New York/London, Routledge, 2011

CARVALHO, J. S. F. Autoridade e educação: o desafio em face do ocaso da tradição. Revista Brasileira de Educação, v. 20, n. 63, 2015, p.975-993. doi:10.1590/S1413-24782015206309

COMENIUS, J. A. The OrbisSensualimPictus. New York: C.W. Bardeen Publicher, (1887) [1685]. Disponível em: <https://archive.org/stream/cu31924032499455\#page/n157/mode/2up>.

FERREIRA, A. C.; SANTOS, E. R.; ROSSO, A. J. Representação Social da Indisciplina Escolar. Revista Psicologia: Teoria e Prática, v. 32, n. 1, 2016, p. 199-208. doi: 10.1590/0102-37722016012074199208

GAUTHIER, C. et al. Por uma teoria da pedagogia: pesquisas contemporâneas sobre o saber docente. ljuí: Editora Unijuí, 2013.

GAUTHIER, C.; BISSONNETTE, S.; RICHARD, M.Ensino explícito e desempenho dos alunos: a gestão dos aprendizados.Petrópolis: Vozes, 2014.

KORPERSHOEK, H.et al. A Meta-analysis of the effects of classroom management strategies and classroom programs on student's academic, behavioral, emotional, and motivational outcomes. Review ofEducationalResearch, v. 20, n. 10, 2016, p. 1-38. doi:10.3102/0034654315626799

LEDO, V. A.A Indisciplina escolar nas pesquisas acadêmicas. 245f. Dissertação (Mestrado em Educação) -Pontíficia Universidade Católica. São Paulo, 2009. Disponível em: <https://sapientia.pucsp.br/handle/ handle/10720>. 
LEWIS, R. et al.Students' reaction to classroom discipline in Australia, Israel and China. Teaching and Theacher Education, v. 24, n. 3, 2008, 715-724. doi:10.1016/j.tate.2007.05.003

LEWIS, R.; ROMI, S; QUI, X.; KATZ, Y. J. Teachers' Classroom Discipline and Student Misbehaviour in Australia, China and Israel, Teachingand Teacher Education,v. 21, n. 6, 2005, p. 729-741.doi:10.1016/j. tate.2005.05.008

LO, Y.; VICENT, C. G.; ROBINSON-ERVIN, P. Culturally responsive classroom management. In EMMER, E. T.; SABORNIE, E. J. (Orgs.)Handbook of classroom management. New York: Routledge, 2015. p. 411-430.

MA, X.; WILLMS, J. D. School disciplinary climate: characteristics and effects on eighth grade achievement. The Alberta Journal of Educational Research, v. 50, n. 2, 2004, p. 169-188. Disponívelem: http://ajer. journalhosting.ucalgary.ca/index.php/ajer/index

MONTGOMERY, L. M. Anne de Green Gables. São Paulo: Martins Fontes, 2009.

MONTUORO, P.; LEWIS, R. Students' perceptions of misbehavior and classroom management. In EMMER, E. T.; SABORNIE, E. J. Handbook of classroom management. New York: Routledge, 2015. p 344-362.

MORICONI, G.; BÉLANGER, J.Student behaviour and use of class time in Brazil, Chile and Mexico: evidence fromTALIS 2013.OECD. 2015. Disponível em: <http://www.oecd-ilibrary.org/education/ student-behaviour-and-use-of-class-time-in-brazil-chile-and-mexico_5js6bhlchwmt-en>.

NASEY, C. (2012). Teachers' use of classroom-based management strategies: a survey of New Zealand teachers. Dissertação (Mestrado em Psicologia Educacional). 107f.MasseyUniversity, Albany, New Zeeland, 2012. Disponível em: <http://mro.massey.ac.nz/handle/10179/3483>.

NING, B. et al. The influence of classroom disciplinary climate of schools on reading achievement: a cross-country comparative study. School Effectiveness and School Improvement: An International Journal of Research, Policy and Practice, mar., 2015, p. 1-26. doi: 10.1080/09243453.2015.1025796

OCDE. Teaching and learning international survey (TALIS). OCDE. 2014. Disponível em: <http://www.keepeek. com/Digital-Asset-Management/oecd/education/talis-2013-results_9789264196261-en\#page4>.

REYNOLDS, D. et al. World class schools: international perspectives on school effectiveness. London/ New York: Routledge, 2002.

REYNOLDS at al. Effective school processes. CHAPMAN at al. The Routledge international handbook of educational effectiveness and improvement: research, policy and practice. London/New York: Routledge, 2016.

ROGERS, B. Gestão de relacionamento e comportamento em sala de aula. Porto Alegre: Artmed, 2008.

SHIMAHARA, N. K. Politics of Classroom Life: classroom management in the international perspective. New York/London: Routledge, 2013.

SILVA, F. L. et al. Procedimentos de gestão da sala de aula de professores de escolas públicas. Revista Travessias, v. 10, n. 3, 2016, p. 99-106. Disponível em: <http://e-revista.unioeste.br/index.php/travessias/ article/view/15041/10238>. 
SILVA, R. R. Disciplina escolar e gestão de sala de aula no campo educacional brasileiro. Revista Educação \& Realidade, v. 41, n. 2, 2016, p. 533-554. doi:10.1590/2175-623646473

SOARES, A. S. A Autoridade do professor e a função da escola. Revista Educação \& Realidade, v. 37, n. 3,2012, p. 841-861. Disponível em: <http://www.ufrgs.br/edu_realidade/>.

SOARES, J. F. O Efeito da escola no desempenho cognitivo de seus alunos. Revista Electrónica Iberoamericana sobre Calidad, Eficacia y Cambio enEducación, v. 2, n. 2, 2004, p. 83-104. Disponível em: <http://www.rinace.net/reice/index.htm>.

SOARES, J. F. Melhoria do desempenho cognitivo dos alunos do ensino fundamental. Cadernos de Pesquisa, v. 37, n. 130,2007, p. 135-160. doi:10.1590/S0100-15742007000100007

TEACHERS are people. Direção: Jack Kinney. 6min. e 12seg. Son., color., Disney, 1952. Disponível em: $<$ https://www.youtube.com/watch?v=ceQ5_9hijfs $>$.

WEINSTEIN, C. S.; NOVODVORKY, I.Gestão da sala de aula: lições da pesquisa e da prática para trabalhar com adolescentes. Porto Alegre: AMGH, 2015 